\title{
EDUCAÇÃO ABERTA: CONCEITOS, CONEXÕES E EXPERIMENTOS EM CURSOS DE LIECENCIATURA E FORMAÇÃO DE PROFESSORES
}

\author{
CURITIBA/PR JULHO/2018 \\ lolanda Bueno de Camargo Cortelazzo－UTFPR - icortelazzo@utfpr.edu.br \\ Tipo: Investigação Científica (IC) \\ Natureza: Descrição de Projeto em Andamento \\ Categoria: Pesquisa e Avaliação \\ Setor Educacional: EDUCAÇÃO SUPERIOR
}

\begin{abstract}
RESUMO
Este texto apresenta a fundamentação teórica de um projeto de pesquisa ação colaborativa sobre educação aberta em cursos de licenciatura. Os objetivos são preparar professores de licenciatura para trabalhar com a educação aberta e a pedagogia aberta; fazer os estudantes experienciarem a educação aberta em atividades avaliativas nos cursos de licenciatura; promover a produção de REA e PEA na abordagem da Pedagogia Aberta com estudantes protagonistas de sua formação inicial e desenvolvimento profissional permanente. As fontes consultadas foram buscadas em sites de governo aberto, de inovação aberta e de educação aberta em diferentes idiomas (inglês, francês, italiano) em estudos de colaboradores, professores e pesquisadores praticantes do governo aberto, da educação e da pedagogia abertas. Como pesquisa qualitativa, explicativa e colaborativa, os dados estão sendo coletados tanto em documentos, artigos, dissertações e teses como nas práticas em atividades presenciais e nos ambientes virtuais utilizados pelos estudantes em cursos de licenciatura e em cursos de especialização da própria universidade e do sistema UAB. A categorização será feita na perspectiva hermenêutica fenomenológica trialética no sentido de apresentar proposições de superação das resistências encontradas.
\end{abstract}

Palavras-chave: Educação aberta. Inovação Aberta. Pedagogia Aberta. Tecnologias Digitais. Formação Professor.

\section{AGRADECIMENTOS}

AGRADEÇO AOS MEUS COLEGAS DE COORDENAÇÃO E AOS MEUS ESTUDANTES QUE COLABORAM COMIGO NESTA PESQUISA. 


\section{Preliminares}

O conceito de Educação Aberta começa a ser delineado no sentido contemporâneo na Comissão Europeia (órgão executivo da União Europeia) no início da década de 2000 quando se preparava um documento para os seus membros. A Educação Aberta não é uma ideia nova, emergente nessa década. Emergiu na década de 1970, na Inglaterra, quando foi criada a British Open University, "uma universidade de ensino a distância aberta a todos" (BATES, 2016, p. 427), principalmente com o objetivo de preparar mão de obra para um mercado de trabalho que se ressentia da carência de trabalhadores especializados. Bates se refere ao fato de "menos de $10 \%$ dos estudantes que terminavam o ensino médio entraram na faculdade". Nessa concepção, não havia prérequisitos para alguns cursos, em outros, já se considerava como créditos a experiência laboral do cursista. Textos impressos, radiodifusão, TV, e produção de filmes e vídeos compõem as mídias utilizadas para "distribuir" os conteúdos que alcançavam estudantes em diferentes regiões do mundo. Bates indica que em 1971, a Open University "iniciou com 25.000 estudantes na admissão inicial e agora tem mais de 200.000 estudantes matriculados". Na década de 1980, a Universidade Aberta Americana (1983) começou a utilizar a rede de computadores para complementar as comunicações entre professores e cursistas; e no final daquela década, a British Open University atendia 1.300 estudantes via rede de computadores, o que levou a educação a distância a incorporar a aprendizagem cooperativa como estratégia educacional (HARASIM et alii, 2005, p.28-29). Ao redor do mundo, em países como Canadá, China, Turquia, Indonésia, e África do Sul, têm universidades abertas públicas e que propiciaram que milhões de estudantes do ensino médio tivessem acesso ao ensino superior (BATES, 2016, p. 428).

No Brasil, a UAB, Universidade Aberta do Brasil, é um consórcio de instituições de ensino superior que usa a rede de computadores e a plataforma de ambiente virtual de aprendizagem Moodle, para oferecer cursos do ensino superior para as "camadas da população que tem dificuldade de acesso à formação universitária, por meio da metodologia da educação a distância. O público em geral é atendido, mas os professores que atuam na educação básica tem prioridade de formação, seguidos dos dirigentes, gestores e trabalhadores em educação básica dos estados, municípios e do Distrito Federal. Hoje, o Sistema é coordenado pela Diretoria de Educação a Distância (DED) da Capes" (BRASIL, 2016).

Em 2018, consolida-se a criação do portal Educapes decorrente de uma política educacional para a educação aberta. O portal Educapes é um espaço para a publicação de objetos educacionais abertos (também conhecidos como OEA e REA) que "estejam 
licenciados de maneira aberta, publicados com autorização expressa do autor ou ainda que estejam sob o domínio público" (BRASIL, 2018).

A educação aberta contemporânea se torna mais abrangente como uma tendência mundial decorrente da política educacional "Educação para todos", emergente nas conferências internacionais da UNESCO, já vistas, desde a década de 1990, que orienta para a aprendizagem aberta, escalável e flexível. Também, precisamos lembrar que ela só é possível devido às grandes transformações tecnológicas no campo da informação e da comunicação e da criação da Web 2.0 que, segundo a Organization for Economic Cooperation and Development (OECD),"é a web participatória com base na Internet cada vez mais influenciada pelos serviços inteligentes da web" permitindo aos usuários contribuírem para a oferta de conteúdos da Internet em suas diferentes fases e "para a customização das aplicações $s$ da Internet na publicação da web participatória e dos conteúdos criados pelos usuários” (OECD, 2007, p. 9 apud TOLEDANO, 2013, p. 2).

Usamos Toledano (2013) como referência, pois ela defende sua tese sob Web 2.0 na perspectiva das Relações Públicas, trazendo nova compreensão da contribuição que a Web participatória pode trazer para a aprendizagem autônoma e permanente. Com essa contribuição, o conceito se amplia e enriquece a área da educação; por essa razão também, emprestamos de sua tese outra conceituação referente à Web 2.0, dada por Tom O' Reilly que a valoriza como plataforma: "Web 2.0 é a rede usada como plataforma, abrangendo todos os artefatos conectados". As aplicações Web 2.0 aproveitam a maior parte das vantagens intrínsecas da plataforma: entregando o software como um serviço em constante atualização que se aperfeiçoa à medida que as pessoas o utilizam, consumindo e remixando dados de múltiplas fontes. Incluem os usuários individuais, enquanto fornece os seus próprios dados e serviços de forma a permitir a remixagem pelo outros, criando efeitos em rede através de uma "arquitetura de participação";, e vai além da metáfora da página da Web 1.0, para proporcionar experiências de usuários mais ricas (REILLY, 2007, p. 2 apud TOLEDANO, 2013, p. 2).

Toledano faz uma série de considerações sobre a comunicação na área de Marketing que são plenamente válidas tanto para a educação básica quanto para a educação superior. Os estudantes são pessoas que querem se comunicar; e precisamos saber 0 que eles estão comunicando nas redes sociais, como eles estão interagindo, como eles estão resolvendo (ou não) seus problemas; e apropriarmo-nos dessa abertura que a Web 2.0 nos oferece para interagirmos com eles.

Em 2007, Paul Andersen ressalta que a colaboração, a contribuição e a comunidade fazem parte da atualidade e são reflexos do poder da Web 2 acessada por um bilhão de 
usuários da Internet. Apresentou as ideias chave que a caracterizam: a produção individual e o conteúdo produzido pelo usuário; a valorização do poder da multidão; os dados circulantes em uma escala grandiosa; a arquitetura da participação; os efeitos da rede; e a abertura. Sobre esta última característica, traduzimos as palavras de Andersen: "O desenvolvimento da Web assistiu uma ampla gama de desenvolvimentos culturais, políticos e regulatórios envolvendo o controle, acesso e direitos do conteúdo digital. Entretanto, a Web teve sempre uma forte tradição de trabalhar de maneira aberta e essa é uma poderosa força da Web 2.0: trabalhar com padrões abertos usar software aberto, usar dados livres, reusar dados; e trabalhar com o espírito da inovação aberta". (ANDERSEN, 2007, p. 25).

Em sua dissertação sobre abertura e pesquisa, Baker (2014) apresenta diferentes perspectivas sobre educação aberta a partir do conceito de Openness (abertura), visto nas abordagens histórica, filosófica, e tecnológica. Da abordagem tecnológica, destacase Meiszner (2011) para quem a educação aberta é entendida: "como o acesso livre e aberto para o uso e o direito de modificar e reusar recursos educacionais abertos digitais e as ferramentas educacionais digitais e o acesso livre e aberto às comunidades educacionais virtuais para aprender, ensinar, compartilhar e avançar no conhecimento de maneira interativa e colaborativa". (MEIZSNER, 2011, p.6 apud BAKER, 2014, p. 7).

Ainda na mesma direção, Bates buscou contextualizar a educação aberta como o movimento em que os Recursos Educacionais Abertos (REA) e os Massive Open Online Courses (MOOC) aparecem e podem ser entendidos no sentido de "livre", isto é, aberto, mas sem custos para o usuário (alunos, estudantes, etc.) (BATES, 2016, 425-445). Na década de 2000, o movimento dos Recursos Educacionais Abertos, REA, e dos Massive Open Online Course, MOOC, apesar dos debates em torno dessa prática, deu um grande impulso à educação aberta, pois os experimentos atuais de MOOC podem ser usados como catalisadores que permitem a exploração de novas oportunidades de educação aberta.

Todas essas formas de abertura na educação implicam um sistema de educação aberta, com planejamento de metas e ações que envolvem a projeção e execução do Desenho Educacional Aberto (DEA), a produção de Recursos Educacionais Abertos (REA), o projeto de Práticas Educacionais Abertas (PEA) e de Práticas Pedagógicas Abertas (PPA), e a definição de uso de licenças como Creative Commons e GNU GPL (General Public License).

Para Baker, Filosofia da Abertura é um sistema de crenças disruptivo e inovador que, quando executado, amplia os sistemas e os processos; encoraja a quebra e a 
superação das fronteiras; e capacita a criação livre, o compartilhamento, o uso, a distribuição e a modificação de propriedades, ideias e conteúdos de forma aberta e colaborativa. (Baker, 2018, web). (tradução nossa). A Abertura Openness é representada em um Mapa conceitual (tendo no centro os Sistemas Educacionais Abertos) e segundo o autor, "é um mapa conceitual mais antigo, mas representa uma perspectiva de como a abertura integra o design instrucional" (BAKER, 2018, nossa tradução).

Por outro lado, Bates (2016) nos chama a refletir sobre a aprendizagem aberta em suas especificidades que variam de acordo com os objetivos das instituições que a oferece. Há uma série de tendências na Internet desde o início da década de 2000. As conferências internacionais influenciaram as políticas educacionais de diversas nações e as possibilidades que a Web 2.0 norteia em suas iniciativas locais. A "educação para todos" que visa atender a ampliação de oferta de oportunidades para os menores de 18 anos; programas formais das universidades abertas abrem acesso à formação e desenvolvimento profissional para as pessoas que desejam se aperfeiçoar e não tem condições de tempo e espaço. Os "Recursos Educacionais Abertos (REA)" são produzidos em programas de instituições formais, também são incentivados como políticas educacionais, como no sistema UAB/CAPES. Também a produção de "livros abertos" disponibilizados online pode ampliar o acesso de estudantes que não têm condições de comprar livros didáticos impressos. Muitas universidades passaram a permitir o "acesso aberto às pesquisas" que são financiadas pelo governo. Assim como os governos que assinaram o acordo da OCDE decidiram que os relatórios financiados pelos seus governos devem estar com seus "dados abertos" em um movimento de transparência.

Consideramos, ainda, para caracterizar a educação aberta, Santos et alii que propõem uma estrutura que se constitui por 10 dimensões, das quais seis são nucleares (acesso, conteúdo, pedagogia, reconhecimento, pesquisa e colaboração) e quatro são transversais (estratégia, tecnologia, qualidade e liderança) (SANTOS et alii, 2016, p. 24). Os autores ainda indicam uma estratégia holística e uma ação institucional colaborativa através de parcerias intrainstitucional (dentro da própria instituição), interinstitucional (entre instituições similares) e transnacional (entre instituições ou organizações de diferentes nações) para trabalhar a educação aberta.

\section{Pedagogia aberta, ensino aberto, aprendizagem aberta}

A educação é composta dos processos de aprender para ensinar, ensinar e aprender. Essa concepção precisa estar muito clara para os professores, que não saem de cena 
com o protagonismo dos estudantes, pelo contrário, assumem um papel que se estabelece como mais nobre do que o transmissor de informações. Os professores que continuam em processo de desenvolvimento profissional contínuo acompanham as transformações, aprendem os conceitos e instrumentos inovadores e os incluem em sua prática pedagógica com a segurança de serem "técnicos" (coaches) competentes de novos aprendizes, permitindo-Ihes a autonomia e tornando-os proativos.

Ao pesquisarmos sobre a pedagogia aberta, encontramos em língua francesa trabalhos sobre a inovação aberta e a pedagogia aberta (DUB, 2013, RICAUD, BENSTEIN, 2017), e constatamos que a nossa ação está muito próxima a essas ações desenvolvidas em outras partes do mundo, pois buscamos maior autonomia e participação dos estudantes no seu processo de conhecimento e aprendizagem que será levado para sua vida pessoal e social, isto é na sua atuação como cidadão. Curiosamente, mas não surpreendentemente, não encontramos literatura sobre esse assunto em língua portuguesa. Por essa razão, estamos usando algumas citações diretas dos autores estudados.

A partir da década de 2010, em uma perspectiva de inovação aberta, muitas nações desenvolvem plataformas abertas de dados públicos para conhecimento e participação de seus cidadãos. Na França, por exemplo, o "data.gouv.fr" tem como lema "Partagez, améliorez et réutilisez les données publiques" (compartilhar, melhorar e reutilizar os dados públicos). Essa plataforma coleta e disponibiliza os dados dos 13 ministérios do governo francês, permitindo a visibilidade e a reutilização dos dados por meio da própria plataforma. No caso, por exemplo, dos institutos de pesquisa espalhados pelo mundo, 0 cidadão pode ter acesso e contribuir, abrindo tópicos de discussão, compartilhando novas bases de dados e reutilizar os dados em infográficos, artigos ou aplicativos (DATA.GOUV.FR, 2018).

Assim, uma nova pedagogia, a pedagogia aberta se constitui na perspectiva da Inovação Aberta que se caracteriza por transparência, cooperação, e participação. Em relação à transparência, a orientação é abrir os dados para conhecimento de todos, utilizando os recursos abertos; dar explicações, utilizando vídeos e mapas conceituais; e mostrar os processos de aprendizagem, os programas e a análise reflexiva. Em relação à cooperação, três fases importantes são: implantar um módulo no ambiente profissional, superando os limites disciplinares; organizar o trabalho pedagógico, trabalhando com a transdisciplinaridade seja com a pedagogia de projetos ou com a resolução de problemas; e organizar as parcerias (com outros departamentos, com parceiros externos - associações, empresas, mídias sociais) deixando aos estudantes a responsabilidade de definir os dados e a exploração que farão deles: "os dados abertos 
existem, proponha uma aplicação pertinente que os explore!" (DUB, 2012). Em relação à participação, permitir que os estudantes tenham sua escolha, sendo sujeitos do estudo, construir em conjunto com a equipe (professores e estudantes) a formação; coletar críticas, ideias, pareceres; e avaliar a formação individual ou em pares (idem). Concordamos com a recomendação que Dub faz em sua apresentação: "A pedagogia aberta é antes de tudo uma abordagem, um estado de espírito, que não precisa obrigatoriamente de saber-fazer tecnológico. Pode-se começar pequeno, por um aspecto que nos pareça especialmente pertinente (recursos abertos, programa do curso, etc.) sem procurar substituir tudo a um só golpe para fazer algo perfeito"... (DUB, 2012)

\section{Um exemplo concreto de Pedagogia Aberta}

Buscamos reorganizar nossa prática pedagógica nos cursos de licenciatura em que atuamos à cada nova aprendizagem no campo da tecnologia e da metodologia de ensino. Nos últimos três últimos semestres, decidimos trabalhar fóruns de discussão como espaço de produção de recursos educacionais abertos (cujos dados são usados na pesquisa). Neste semestre, além da produção dos REA inclusivos, decidimos instigar os estudantes de Letras, Física e Química a estudarem a legislação sobre inclusão na escola, comparando a legislação brasileira com a de um país de língua inglesa que eles escolhessem (em equipe).

As turmas de 2017 demonstraram uma resistência à abertura (que Ihes atribuía uma responsabilidade não usual) de produção por parte de alguns estudantes, abandono da disciplina, por outros, e a realização de REA surpreendentes por outros, como a produção de REA para atender a orientação de professores que não tinham preparo para a educação inclusiva; construíram blogs nos quais aplicaram o conceito de curadoria digital. A comunicação da equipe era registrada no espaço do fórum de discussão em paralelo à construção do blog. Uma das equipes, composta por alunos que eram músicos, focou na produção de um vídeo para o ensino de som a surdos, utilizando tópicos do ensino de Física, gravando em um estúdio e utilizando aplicativos para demonstrar visualmente as ondas sonoras na produção de diferentes timbres, frequências e alturas. Outras equipes, ao serem cobradas pela ausência de registros de suas atividades no Fórum, indicaram que estavam se comunicando pelo Googledocs, pelo whatsapp, ou no próprio blog que estavam construindo. Aprendemos que os estudantes tinham suas próprias redes e preferências por espaços de compartilhamento. Ensinamos que a abertura é criativa, inovadora e necessária, mas que também são necessários alguns formalismos, visto que a educação aberta não significa educação sem escola. Aprendemos que o respeito a seus espaços, sua iniciativa e sua proatividade enriquecem o processo de aprendizagem. Ensinamos-Ihes que o controle 
escolar formal é indispensável para a sua avaliação e certificação. Aprendemos, mais uma vez, que a colaboração estimulada dentro das regras que lhe são próprias (interdependência, respeito, divergência) propicia uma aprendizagem significativa e o compartilhamento responsável. Ensinamos-lhes, ainda que a divergência, o escuta do outro, o respeito às decisões de consenso demonstram amadurecimento pessoal e social.

Na perspectiva da inovação e da pedagogia abertas, orientamos o acesso à web e às legislações disponíveis nas plataformas dos governos (brasileiro e dos escolhidos). Cada equipe poderia fazer a sua apresentação de acordo com a sua escolha (jornal falado, dramatização, entrevista, etc.).

Os estudantes estão em pleno desenvolvimento deste trabalho, mas algumas equipes já apresentaram sua produção. Observamos que a forma de apresentação da maioria continua sendo o seminário tradicional de se preparar uma apresentação em PowerPoint, embora uma das equipes tivesse desejado preparar um podcast, a maioria dos estudantes da equipe decidiu pela apresentação tradicional. Porém, o que foi muito alentador é que o processo de preparação foi colaborativo, estudantes de Física e de Química trabalharam na pesquisa com os estudantes de Letra Inglês, pesquisando e compartilhando no espaço do Fórum. Não com cópias de trechos de textos, mas com sinopses de sites visitados, de artigos lidos, de legislação estudada. Nas nossas avaliações, como sempre fazemos em cursos de licenciatura, reforçamos as orientações tanto do ponto de vista do conhecimento como das habilidades e atitudes que os estudantes precisam desenvolver como profissionais da educação que serão ao se licenciarem.

$\mathrm{Na}$ perspectiva da pedagogia aberta, constatamos que os estudantes em sua apresentação em sala de aula, em forma de seminário, estavam seguros e distribuíram as falas entre todos, demonstrando com suas intervenções durante as falas dos colegas, que todos que se propuseram a participar, participaram de fato. Constatamos que alguns estudantes se tornaram mais exigentes dos resultados dos desempenhos dos colegas. Nos ambientes virtuais, a participação era diferenciada pelo estilo de aprendizagem dos estudantes e pelo seu comprometimento. Nossa avaliação nesses ambientes, também os direciona a considerarem tanto a sua formação pessoal quanto a profissional, indicando-lhes possibilidades de se aproximarem do seu contexto profissional em que atuarão. Estamos preparando a postagem desses REA no repositório da Educapes.

Nesta experiência pedagógica, o relatório do trabalho, incluindo seu making of foi 
realizado em um wiki de cada equipe, que a princípio começou a ser feito só pelo relator da equipe, mas que acabou por ter a participação de todos como solicitado nas orientações da atividade.

A partir de nossas pesquisas sobre a nossa própria prática, constatamos que quanto mais abrimos para que os estudantes utilizem as plataformas abertas e os responsabilizamos por sua aprendizagem, mantendo, certo controle necessário em uma instituição de ensino formal, mais a sua participação, o seu protagonismo e a sua responsabilidade convergem para uma aprendizagem significativa. Constatamos, porém, que a resistência de boa parte dos estudantes é grande, pois ainda se prendem às práticas pedagógicas transmissivas ou instrucionais de muitos dos docentes universitários.

Aprendemos ainda que ao aplicarmos a pedagogia aberta com nossos estudantes nos cursos de licenciatura, utilizando uma metodologia de ensino híbrido, períodos oficiais de aulas presenciais e atividades avaliativas assíncronas mediadas pelos ambientes virtuais de aprendizagem e outros espaços digitais, precisamos explicitar os objetivos dessa metodologia de forma exaustiva para os estudantes; demonstrar os conhecimentos construídos por eles; fazê-los conscientes do sentido e significado que essa aprendizagem assume em sua formação profissional.

Constatamos, ainda que a compreensão do que é uma rede de aprendizagem ainda é limitada para a maioria dos estudantes, como também é limitada para a maioria dos docentes. Esse tema precisa ainda ser muito debatido e pesquisado.

\section{Referências}

ANDERSON, Paul.What is Web 2.0? Ideas, technologies and implications for education. JISC. Technology \& Standards Watch. Disponível em: $<$ http://www.jisc.ac.uk/media/documents/techwatch/tsw0701b.pdf>. Acesso em: $20 \mathrm{mar}$. 2018.

BAKER III, Fredrick William. Openness. Disponível em: <http://www.fredwbaker.com/openness/>. Acesso em: 10 abr. 2018

BAKER III, Fredrick William. Policies related to the implementation of openness at research intensive universities in the United States: A descriptive content analysis. University of South Alabama, 2014, 356 p. Disponível em: $<$ https://pqdtopen. proquest.com/doc/1638267596.html?FMT=Al\&pubnum=3645569>. 
Acesso em: 10 abr. 2018.

BASTIEN, L. Open Data définition: Qu'est-ce que c'est ? À quoi ça sert ? Le Big Data. Publicado em 16/11/2017. Disponível em: <https://www.lebigdata.fr/open-datadefinition>. Acesso em 14 mai. 2018.

BATES, A. W. (Tony). Tendências em Educação Aberta. Educação na era digital: design, ensino e ensino e aprendizagem. São Paulo: Artesanato Digital, 2016, p. 421-450 ensino e aprendizagem. São Paulo: Artesanato Digital, 2016, p. 421-450.

BRASIL. CAPES. EDUCAPES. Disponível em: < https://educapes.capes.gov.br/>. Acesso em:10 mai. 2018.

BRASIL. CAPES.UAB. Publicado em 06/10/2015. Última Atualização: 27/03/2018. Disponível em: <http://www.capes.gov.br/acessoainformacao/perguntasfrequentes/educacao-a-distancia-uab/4144-o-que-e> . Acesso em 18 mai. 2018.

DATA,GOUV.FR. Plateforme ouverte des données publiques françaises. Disponível em: < https://www.data.gouv.fr/fr/>. Acesso em: 10 mai.2018.

DUB, Jack. Pédagogie ouverte: présentation à partir d'un exemple. PRODAGEO CC Publicado em 27 novembro 2012. Disponível em: <https://prodageo.wordpress.com/2012 /11/27/pedagogie-ouverte-presentation-a-partir-dun-exemple/>. Acesso em:10 mai. 2018.

HARASIM, Linda; TELES, Lucio; TUROFF, Murray; HITZ, Star Roxanne. Redes de Aprendizagem: um guia para ensino e aprendizagem on-line. São Paulo: SENAC, 2005.

SANTOS, Andreia Inamorato. Referencial Europeu de Educação Aberta - OpenEdu Framework. Disponível em: <https://www.youtube.com/watch?v=yE8q6MWvcw>. Acesso em: 23 abr. 2018.

TOLEDANO, Cristina Aced. Web 2.0: the origin of the word that has changed the way we understand public relations. Disponível em <https://www.researchgate.net/publication/26 6672416_Web_20_the_origin_of_the_word_that_has_changed_the_way_we_understan d_public_relations>. Acesso em 28 abr. 2018. 